\title{
Energy Efficient Microwave Irradiation of Sago Bark Waste (SBW) for Bioethanol Production
}

\author{
T. Saravana Kannan ${ }^{1, a}$, A. S. Ahmed ${ }^{2, b}$ and F.N. Ani, \\ ${ }^{1}$ Faculty of Engineering, Computing and Science, Swinburne University of Technology, Kuching, \\ Sarawak, Malaysia \\ ${ }^{2}$ Department of Mechanical and Manufacturing Engineering, Faculty of Engineering, Universiti \\ Malaysia Sarawak, Sarawak, Malaysia \\ ${ }^{3}$ Faculty of Mechanical Engineering, Universiti Teknologi Malaysia, Skudai, Johor D.T., Malaysia \\ asthangavelu@swinburne.edu.my, baasaleh@feng.unimas.my, ${ }^{c}$ farid@fkm.utm.my
}

\begin{abstract}
Keywords: Sago bark waste (SBW), bioethanol, microwave irradiation, energy efficiency
\end{abstract}
\begin{abstract}
The energy efficiency of microwave irradiation for bioethanol production from sago bark waste (SBW) was studied. The maximum sugar yield of $62.6 \%$ was reached at the biomass loading $20 \%(\mathrm{w} / \mathrm{w})$. The high ethanol yield of $60.2 \%$ theoretical yield, ethanol concentration $30.67 \mathrm{~g} / \mathrm{l} \mathrm{was}$ achieved by diluted sulfuric acid supported microwave irradiation with $40 \%(\mathrm{w} / \mathrm{w})$ biomass loading at $60 \mathrm{~h}$ fermentation. The energy consumption of microwave irradiation to produce $1 \mathrm{~g}$ sugar and $1 \mathrm{~g}$ ethanol was calculated separately. The lowest energy consumption was noticed while biomass loading and energy input were fixed at $40 \%(\mathrm{w} / \mathrm{w})$ and $33 \mathrm{~kJ}(1100 \mathrm{~W}$ for $30 \mathrm{~s})$ respectively, and it is amounted to 1.27 and $1.76 \mathrm{~kJ}$ to produce $1 \mathrm{~g}$ of sugar after enzymatic hydrolysis and $1 \mathrm{~g}$ ethanol after fermentation, individually. Usually, $1 \mathrm{~g}$ ethanol can produce approximately $27 \mathrm{~kJ}$ of energy, and therefore, the energy input for the microwave pretreatment was only $7 \%$ of the energy output. The microwave irradiation technique established for SBW to produce ethanol succeeded in $80 \%$ energy savings for producing $1 \mathrm{~g}$ ethanol compared to rape straw by microwave pretreatment previously reported.
\end{abstract}

\section{Introduction}

The use of bioethanol in the transport sector can save significant amount of fossil fuels and reduce greenhouse gas emission. Currently, ethanol production based on corn starch and sugar substances may not be desirable due to their food as feed value. Lignocellulosic biomass is renewable, low cost and is abundantly available globally [1]. In Sarawak, the waste from sago starch processing industry such as sago bark (peelings from initial processing), sago 'hampas' (fibrous byproducts from crushing and sieving) and sago waste water can be used as promising renewable and cheap starchy lignocellulosic biomass feedstock for bioethanol production as well as avoiding the need for alternative waste management. Since it contains starch, cellulose and hemicellulose bound together by lignin, hence requires suitable economic pretreatment for the efficient utilization of biomass for ethanol production [2].

Various pretreatment techniques such as steam exploitation, hydrothermal, ultrasound and wet oxidation were reported for lignocellulosic biomass, however these methods are difficult to implement for commercial level of production because of high energy and pressure requirements [3]. Microwave treatment is an energy efficient physico-chemical pretreatment and it is easy to implement for commercial level. Both thermal and non-thermal effects are applied to biomass using microwave irradiation to change the ultra-structure of starch, cellulose and hemicellulose. This is to increase the enzymatic susceptibility of lignocellulosic residues and also degrade the lignin rapidly [2]. Microwave pretreatment have been used for rice straw [4], wheat straw [5], sugar cane baggage [6], sweet sorghum bagasse [7], switch grass [8] and rape straw [9]; and ethanol yields are higher than conventional pretreatments. Before implementing microwave treatment, it is essential to determine the energy consumption of this technique which is good enough to achieve economical ethanol 